\title{
Definitions of and Perspectives on Forests of High Value: A Systematic Map Protocol
}

\author{
Sini Savilaakso ${ }^{1,2, *(\mathbb{D})}$, Nik Lausberg ${ }^{1}$, Claude A. Garcia ${ }^{1,3}{ }^{\mathbb{D}}$, Raymond Grenacher ${ }^{4}$, Fritz Kleinschroth ${ }^{5}$ \\ and Patrick O. Waeber $1, *$ (D)
}

1 Forest Management and Development, Department of Environmental Systems Science, Institute of Terrestrial Ecosystems, ETH Zürich, 8092 Zürich, Switzerland; nikla@student.ethz.ch (N.L.); claude.garcia@usys.ethz.ch (C.A.G.)

2 Liljus Ltd., 3rd Floor, 7 Moorgate, London EC2R 6AF, UK

3 CIRAD, UPR Forêts et Sociétés, F-34398 Montpellier, France

4 ETH-Library, ETH Zürich, 8092 Zürich, Switzerland; raymond.grenacher@library.ethz.ch

5 Ecosystem Management, Department of Environmental Systems Science, Institute of Terrestrial Ecosystems, ETH Zürich, 8092 Zürich, Switzerland; klfritz@ethz.ch

* Correspondence: sini.savilaakso@gmail.com (S.S.); patrick.waeber@usys.ethz.ch (P.O.W.)

Citation: Savilaakso, S.; Lausberg,

N.; Garcia, C.A.; Grenacher, R.;

Kleinschroth, F.; Waeber, P.O.

Definitions of and Perspectives on

Forests of High Value: A Systematic

Map Protocol. Forests 2021, 12, 876.

https://doi.org/10.3390/f12070876

Academic Editor: Gillian Petrokofsky

Received: 30 April 2021

Accepted: 30 June 2021

Published: 2 July 2021

Publisher's Note: MDPI stays neutral with regard to jurisdictional claims in published maps and institutional affiliations.

\begin{abstract}
Forests are defined in many different ways. Apart from ecological and structural factors, associated values and provided ecosystem services are an important part of forest definitions. Typically, forest types are differentiated based on climatic regions and on degrees of human modification. A better understanding of how to distinguish different forests on the basis of the values they provide is needed to advance global policies put forward by organisations such as the Convention on Biological Diversity (CBD), the United Nations Framework Convention on Climate Change (UNFCCC), or the UN Sustainable Development Goals (SDGs). These policies so far approach all forests in a similar manner, regardless of their condition. Without this distinction, benefits stemming from forest intactness and their contribution to global environmental challenges remain unaccounted for. Forest definitions provide the basis for policies and monitoring systems driving or enabling deforestation, degradation, reforestation, and restoration. Here, we provide a systematic approach to disentangle and synthesise different value classifications of forests. As part of a collaboration between ETH Zurich, the French Agricultural Research Centre for International Development (CIRAD), the University of Liège and Biotope, Forest Stewardship Council International (FSC) commissioned a systematic map that aims to clarify how definitions of forests of high value are understood and described. Focusing on forests of high value, the systematic map will address three research questions: (1) How are various terms linked to forests of high value defined in the literature?; (2) Do definitions vary between different actors?; and (3) How common are the various definitions? Bibliographic databases and organisational websites will be searched, and internet search engines used to find relevant peer-reviewed and grey literature. The searches will be conducted in English, French and Spanish. Data extraction and coding will be performed at the same time when full texts are considered for inclusion. Definitions will be extracted as well as their respective sources and other study information. We will produce a catalogue of definitions for different terms associated with forests of high value, a narrative synthesis describing the evidence base, and visualisations illustrating the relationships between definitions and terms for forests of high value and their frequencies in the literature.
\end{abstract}

Keywords: intact forest landscapes; high conservation value; forest biodiversity hotspots; primary forest; old-growth forest; indigenous people; definition; meaning

\section{Background}

Forest loss is a key driver of global biodiversity loss, carbon emissions, and climate change [1]. Environmental policies and decisions to protect and restore forests that ulti- 
mately decide the future of forests and that of the people who rely on them are shaped by how humans define forests [2].

There are a plethora of concepts used to describe forests, reflecting tree height and density, forest structure, composition, dynamics, size, human activity, rights, quality or value. Forest value definitions are particularly difficult to grasp, because they differ between viewpoints and normative systems. Examples of such terms include definitions related to the degree of human influence such as 'intact forests' as well as 'ancient forests' and 'primary forests'. These terms are used differently by different institutions and stakeholders. Unintended consequences arise when definitions associated with such terms are used beyond their scope of relevance.

An example for this ambivalence is the definition of a primary forest from the Forest Resource Assessment [3,4]. They define primary forests as "naturally regenerated forests of native species where there are no clearly visible indications of human activities and the ecological processes are not significantly disturbed. Primary forests-especially primary tropical moist forests-are highly species-rich, diverse ecosystems, and their extent is an important environmental indicator." [3] (p. 7). This definition allows for subjectivityvisible indications of human activity may be perceived differently by trained and untrained observers-and can lead to inconsistencies on how the same forests are categorized on a global scale [5]. This definition is not operational; therefore, different countries and stakeholders apply the term 'primary forest' in different ways. Terms such as 'pristine forest', 'ancient forest', 'intact forest', 'untouched forest', inter alia, have been used interchangeably for 'primary forest' [6]. This, in turn, leads to significant differences in how countries assess and evaluate their primary forest areas. Definitions can also have a nested structure, which compounds the challenges we face. For example, the Food and Agriculture Organisation of the United Nations (FAO) definition of forest disturbance introduces the concept of ecosystem services-not used in the definition of forests. This constitutes inconsistencies that create opportunities for loopholes or misinterpretations. Oversimplified forest definitions can also lead to the risk of obscuring substantial losses in what most people value as forest [7]. These difficulties are well recognized by major institutions working and communicating on the issue, e.g., the FAO has made its glossary explicit and public, and Global Forest Watch (https:/ /www.globalforestwatch.org/) has made efforts to clarify the distinction it makes between forest loss and tree cover loss.

\section{Valuing Forests}

Across the globe, forests are valued for many different aspects by different groups of people. Here, we focus on value classifications of forests that are related to forest age and different degrees of human modification. Recently, the preservation of intact forests has gained traction in the conservation field [8]. Such large forests that are free of major human modifications are associated with inherent values stemming from the idea of maintaining wild places in a world where the surface is largely shaped by humans. At the same time, such forests often provide major net carbon sinks [9] and are important for the conservation of specialist, disturbance-sensitive species, such as woodland caribou in boreal Canada [10]. Some 1.6 billion people live within $5 \mathrm{~km}$ of a forest, with many of them, including indigenous peoples, being dependent on their ecological functioning [11]. For forest-dependent people, the value of forests lies in cultural identities, homes and lifestyles that would be lost if the forest were degraded or removed. However, indigenous management does not necessarily maintain forest intactness in the strict sense, because the dichotomy between conservation and development is not reflected in the understanding of using forests in a stewardship approach as practiced by many indigenous peoples [12]. To capture such cultural values in a better way, the concept of indigenous cultural landscapes (ICLs) has been suggested instead of the intact forest landscapes (IFLs) concept [13].

Along with many other non-timber forest products (such as bushmeat, fruits, nuts and vegetables), forests are also a major source for many medicinal compounds that benefit people worldwide [14]. The degree of ecosystem services varies from forest to forest as the 
perceived importance of forests changes from one stakeholder to another. Frameworks such as the Nature Futures Framework recently presented by the Intergovernmental Science-Policy Platform on Biodiversity and Ecosystem Services (IPBES) propose a way to acknowledge this plurality of perceptions [15].

The ambiguity of definitions surrounding forests represents a challenge for meaningful and effective policies and regulations, which has knock-on effects on the implementation of sustainable management actions. For example, using the term "IFL" in Motions 2014/07 and 2014/65, members of the Forest Stewardship Council (FSC) intended to strengthen landscape-scale protection in the high conservation value framework to conserve biological, ecological, social or cultural values of outstanding significance at the national, regional or global level or of critical importance at the local level (following the consensus-oriented chamber system within FSC, Motions are voted for during general assemblies every three years. Once accepted, they are binding and have to be implemented by the FSC administration). Academics defined IFLs as "a seamless mosaic of forest and naturally treeless ecosystems with no remotely detected signs of human activity and a minimum area of $500 \mathrm{~km}^{2}$ " [16] (p. 1). The FSC adopted the definition, "a territory within today's global extent of forest cover which contains forest and non-forest ecosystems minimally influenced by human economic activity, with an area of at least $500 \mathrm{~km}^{2}(50,000 \mathrm{ha})$ and a minimal width of $10 \mathrm{~km}^{\prime \prime}$. Both definitions are subtly but significantly different, the latter giving room for interpretation as to what the minimal influence could be. In tropical rainforests, this is particularly relevant regarding selective logging operations that can be carried out in biodiversity-friendly ways [17] but are still detectable through remote sensing due to the presence of roads [18]. When academics report on the loss of IFLs within FSC-certified concessions, they are measured according to their remote-sensing definition, which is not the one FSC members have adopted. In other words, the yardstick used to measure performance has not been agreed upon by those whose forests are measured-a fact obscured by the adoption of the same terminology. Forest concepts with similar goals can contradict or work antagonistically to one another [19].

"Forest definitions provide the conceptual, institutional, legal, and operational basis for the policies and monitoring systems that drive or enable deforestation, forest degradation, reforestation, and forest restoration" [2]. Forest definitions are necessary to reach forest management objectives [1]. In this case, agreement is more important than clarity [20]. To build agreement on the definition for forests of high value, in particular, it is critical to identify the definitions that exist in the literature, recognize by whom they are made, and to understand whether there are gaps in the knowledge.

\section{Stakeholder Engagement}

FSC Focus Forests is a collaboration between research institutions (ETH Zurich, the French Agricultural Research Centre for International Development (CIRAD), the University of Liège and Biotope) and FSC to explore FSC's role in the wider forest landscapes with high importance for climate change, biodiversity, or other social and environmental values. As part of the collaboration, FSC International commissioned this systematic map to identify how terms associated with forests of high value are understood, described, and defined, by whom, and which definitions have the greatest saliency in the literature. This overview will assist in clarifying what such forests represent for different actors, as a basis to building any needed agreements.

Before the protocol was submitted to a peer-review, it was sent to FSC Members and other stakeholders engaged with the Focus Forests collaboration for comments on 9 April 2021. Comments were sought especially related to search terms and organisational sources of literature, but stakeholders had access to the full protocol and could comment on any element. Comments were collected for two weeks, and stakeholders had permission to share the protocol with any interested parties. Suggestions from the stakeholders have been integrated into the protocol. 


\section{Objective of the Systematic Map}

Systematic maps provide an overview of the distribution and abundance of evidence in relation to a question of policy or management relevance. This proposed systematic map seeks to examine the range of definitions linked to the term "forests of high value" in the published literature to facilitate the creation of a unifying definition.

The primary question of this systematic map is:

- How are terms linked with forests of high value defined in the literature?

The secondary questions are:

- Do definitions vary between different actors?;

- Are there differences between actors on what definitions are used?;

- How common are the various definitions?

The results of the systematic map will contribute to broader understanding of the meanings of 'forests of high value', and, in a combination with a geographical map of forests of high value, will form a basis to develop research recommendations on management strategies for the respective forests. Managed forests are excluded from this systematic map, although they can be of high value because of ecosystem services they provide. However, their definitions are rather clear and usually linked to their management goals. The value they provide is addressed in other components of the project to be incorporated in the overall goal of clarifying what different forests represent for different actors.

Together with a socially informed framework on the contribution of forests of high value to the wellbeing of different stakeholders, the systematic map will help to organise innovative ways to involve stakeholders in developing landscape use scenarios. Moreover, the research recommendations will lay a new foundation and grant a new perspective for the controversial discussions on IFLs within FSC membership since the approval of the motions 2014/07 and 2014/65.

\section{Definition of Question Components}

We used the PerSPEcTiF framework [21] to outline the key question elements (Table 1).

Table 1. Components of the study question.

\begin{tabular}{cccccc}
\hline Perspective & Setting & Phenomenon of Interest & Environment & Timing & Findings \\
\hline actors & global & $\begin{array}{c}\text { definitions linked with } \\
\text { forests of high value }\end{array}$ & $\begin{array}{c}\text { forest policy, } \\
\text { management and } \\
\text { conservation }\end{array}$ & $\begin{array}{c}\text { since } \\
2005\end{array}$ & saliency \\
\hline
\end{tabular}

\section{Methods}

\subsection{Search Terms and Languages}

The initial search terms in English were proposed by the FSC (Table 2). To ensure comprehensiveness of the search, we added complementary and synonymous terms.

Development of the search string was an iterative process. A scoping exercise was conducted in Web of Science Core Collection (see below the included databases) and Scopus to evaluate the sensitivity of alternate search terms (see File S1 for details). In the search string, keywords representing natural or near-natural forest types are combined with habitat terms and anthropocentric terms. Boolean operators AND and OR are used to combine the different terms and ${ }^{*}$ to identify words with plural forms. The final search string is presented below in the Web of Science format:

TS = (("Stable forest" OR "Stable woodland" OR “Primary Forest*" OR "Primary Woodland*" OR “Ancient Forest*" OR "Ancient Woodland" OR "Old-Growth Forest*" OR “Old-growth Woodland"” OR “Endangered Forest" "Endangered Woodland" ${ }^{* \prime}$ OR "hinterland forest*" OR "hinterland woodland" ${ }^{* \prime}$ OR "intact forest*" OR "intact woodland" ${ }^{*}$ OR "pristine forest" OR "pristine woodland" OR "natural forest*" OR "natural woodland*" OR "undisturbed forest" OR "undisturbed woodland" 
OR "native forest*" OR "native woodland" $\mathrm{OR}^{* \prime}$ "sacred forest*" OR "sacred woodland") OR ((Forest* OR Woodland*) AND ("High Conservation Value" OR "Biodiversity hotspot" OR "Threatened Ecosystem*" OR "Key Biodiversity Area*" OR "Critical habitat" OR ((Indigenous OR native OR "first nation" OR aboriginal OR autochthonous) AND (tribe OR tribal OR community OR communal OR communities OR people))))).

Searches of bibliographic databases and the internet will be conducted in English, Spanish and French. Organisational websites will be searched for unique publications in each of the languages where possible.

Table 2. Keywords considered in this study. All the listed terms with the ending 'forest' will also be searched with the alternate ending 'woodland'.

\begin{tabular}{cc}
\hline FSC Proposed Terms & Additional Relevant Terms for Scope \\
& hinterland \\
primary forest & intact forest \\
ancient forest & high conservation value (HCV) \\
pristine forest \\
intact forest landscapes & natural forest \\
old-growth forest & undisturbed forest \\
endangered forest & stable forest \\
threatened ecosystems (IUCN Red List) & native forest \\
forest biodiversity hotspots & sacred forest \\
Key Biodiversity Areas & aboriginal \\
critical habitats & native people \\
Indigenous people & native community \\
Indigenous community & First Nation \\
& autochthonous \\
& tribe \\
& Indigenous cultural landscapes (ICL)
\end{tabular}

\subsection{Estimating the Comprehensiveness of the Search}

A test list of 20 articles was compiled (File S2) and used to assess whether the search string captured articles identified as relevant to the topic and containing a definition. The final search string captured all 20 articles.

\subsection{Publication Databases}

The Web of Science Core Collection (WoS), Scopus, and the CABI Forest Science Database will be searched. The following WoS databases will be searched:

- $\quad$ Citation Index Expanded (SCI-EXPANDED);

- Social Sciences Citation Index (SSCI);

- $\quad$ Arts \& Humanities Citation Index (A\&HCI);

- Conference Proceedings Citation Index- Science (CPCI-S);

- Conference Proceedings Citation Index- Social Science \& Humanities (CPCI-SSH);

- Book Citation Index-Science (BKCI-S);

- Book Citation Index-Social Sciences \& Humanities (BKCI-SSH);

- Emerging Sources Citation Index (ESCI).

Articles published since 2005 will be searched. The cut-off year 2005 was chosen because this represents the year when the Millennium Ecosystem Assessment [22] was published and values of forests, in addition to timber, came into prominence. Additionally, 2005 is the year the High Conservation Value Resource Network (https: / /hcvnetwork.org/) was established, generalising and institutionalising the High Conservation Value (HCV) concept introduced in the Principle \#9 of FSC in 1999 (https: / / fsc.org/en/document-centre/ documents/resource/392.1). HCV has today become a central element of sustainability standards for products such as palm oil, soy, biofuels or carbon. The terms HCV and HCVA (High Conservation Value Area) are also widely used in landscape mapping, conservation, natural resource planning and advocacy. 


\subsection{Additional Searches}

\subsubsection{Forest Terminology Database}

We will search the SilvaTerm Database (https://www.iufro.org/science/special/ silvavoc/silvaterm/) for definitions of the terms listed in Table 2. The SilvaTerm Database is a terminological database for forestry built by SilvaVoc, a project on forest terminology by the International Union for Forest Research Organisations (IUFRO).

\subsubsection{Internet Searches}

We will use Google Scholar and Google search engines. To avoid biased results due to tailored personal Google accounts, 'private mode' will be used to prevent the influence of previous browsing history and location on search results. The results will be organised by relevance. After the first 100 hits, results will be checked until relevant articles are no longer retrieved, as advised in Livoreil et al. [23]. Simplified search strings will be used due to limited capabilities of the search function. In Google Scholar, the following search strings will be used:

1. ("Primary Forest*" OR “Ancient Forest*" OR "Intact Forest Landscape*” OR “OldGrowth Forest ${ }^{* \prime}$ OR "Endangered Forest*" OR "hinterland forest*" OR "intact forest" OR "pristine forest*" OR "natural forest" ${ }^{*}$ " OR "undisturbed forest*" OR "native forest" OR "sacred forest*");

2. ("Primary Woodland" OR "Ancient Woodland" OR "Old-growth Woodland" OR "Endangered Woodland*" OR "hinterland woodland" OR "intact woodland" OR "pristine woodland" OR "natural woodland" $\mathrm{OR}^{*}$ "undisturbed woodland" OR "native woodland" OR "sacred woodland");

3. ((Forest* OR Woodland $\left.{ }^{*}\right)$ AND ("High Conservation Value" OR "Biodiversity hotspot ${ }^{*}$ " OR “Threatened Ecosystem" ${ }^{*}$ OR "Key Biodiversity Area*" OR "Critical habitat" $\left.{ }^{* \prime)}\right)$;

4. ((Forest* OR Woodland*) AND ((Indigenous OR native OR "first nation" OR aboriginal OR autochthonous) AND (tribe OR tribal OR community OR communal OR communities OR people))).

In Google, all keywords with the term 'forest' will be searched in combination with 'definition'. In addition, the same terms will be searched by replacing forest with 'woodland'. Search strings used, along with the date and number of hits received, will be recorded and included in the final report.

\subsubsection{Searches of Organizational Websites}

Simplified search strings or key words will be used to search organisational websites (Table 3). We have categorised organisations into environmental non-governmental organisations (ENGO), private sector, network, certification, research, and intergovernmental organisations, following [2], to ensure the coverage of organisations from different sectors. In addition, the organisation needs to have direct activities with forests or forest matters and have at least a regional outreach. All searches will be recorded and reported in the final report.

Table 3. Organisational websites that will be searched.

\begin{tabular}{|c|c|c|}
\hline Organisation & Website & Class \\
\hline ATIBT & https://www.atibt.org/en & Network \\
\hline Center for International Forestry Research & https://www.cifor.org/ & Research organisation \\
\hline European Forest Institute & https://efi.int/ & Intergovernmental organisation \\
\hline Fairtrade International & https://www.fairtrade.net/ & Certification organisation \\
\hline Fern & https://www.fern.org/ & ENGO \\
\hline $\begin{array}{l}\text { Food and Agriculture Organisation of the } \\
\text { UN }\end{array}$ & http://www.fao.org/home/en/ & Intergovernmental organisation \\
\hline Forest Legality Initiative led by WRI & https:/ / forestlegality.org/ & ENGO \\
\hline Forest Stewardship Council & https://fsc.org/en & Certification organisation \\
\hline $\begin{array}{l}\text { French Agricultural Research Centre for } \\
\text { International Development }\end{array}$ & https://www.cirad.fr/en & Research organisation \\
\hline Friends of the Earth International & https://www.foei.org/ & ENGO \\
\hline
\end{tabular}


Table 3. Cont.

\begin{tabular}{|c|c|c|}
\hline Organisation & Website & Class \\
\hline $\begin{array}{l}\text { Global Partnership on Forest Land } \\
\text { Restoration }\end{array}$ & \multirow{3}{*}{$\begin{array}{l}\text { https: } \\
\text { //www.forestlandscaperestoration.org/ } \\
\text { https: } \\
\text { //www.greenpeace.org/international/ } \\
\text { https://hcvnetwork.org/ }\end{array}$} & Network \\
\hline Greenpeace & & ENGO \\
\hline High Conservation Resource Network & & Network \\
\hline $\begin{array}{l}\text { International Social and Environmental } \\
\text { Accreditation and Labelling Alliance }\end{array}$ & https://www.isealalliance.org/ & Network \\
\hline International Tropical Timber Organisation & https://www.itto.int/ & Intergovernmental organisation \\
\hline $\begin{array}{l}\text { International Union for Conservation of } \\
\text { Nature and Natural Resources }\end{array}$ & https://www.iucn.org/ & Intergovernmental organisation \\
\hline $\begin{array}{l}\text { International Union of Forest Research } \\
\text { Organizations }\end{array}$ & https://www.iufro.org/ & Network \\
\hline ProForest & https://www.proforest.net/ & ENGO \\
\hline Program on Forest & https://www.profor.info/mission & Network \\
\hline Programme for the Endorsement of Forest & https://www.pefc.org/ & Certification organisation \\
\hline PROGREEN & $\begin{array}{l}\text { https://www.worldbank.org/en/ } \\
\text { programs/progreen }\end{array}$ & Intergovernmental organisation \\
\hline Rainforest Alliance & https://www.rainforest-alliance.org/ & ENGO \\
\hline Roundtable for Sustainable Palm Oil & https://rspo.org/ & Certification organisation \\
\hline Stora Enso & https://www.storaenso.com/ & Private sector \\
\hline The Nature Conservancy & https://www.nature.org/en-us/ & ENGO \\
\hline UN Convention on Biological Diversity & https://www.cbd.int/ & Intergovernmental organisation \\
\hline UN Forum on Forest & $\begin{array}{l}\text { https: } \\
\text { //www.un.org/esa/forests/index.html }\end{array}$ & Intergovernmental organisation \\
\hline $\begin{array}{l}\text { UN Framework Convention on Climate } \\
\text { Change }\end{array}$ & https://unfccc.int/ & Intergovernmental organisation \\
\hline UN Permanent Forum on Indigenous Issues & $\begin{array}{l}\text { https://www.un.org/development/desa/ } \\
\text { indigenouspeoples/unpfii-sessions-2.html }\end{array}$ & Intergovernmental organisation \\
\hline West Fraser Timber & https://www.westfraser.com/ & Private sector \\
\hline World Agroforestry & https://www.worldagroforestry.org/ & Research \\
\hline World Resources Institute & https://www.wri.org/ & Research \\
\hline World Wide Fund for Nature & https://www.worldwildlife.org/ & ENGO \\
\hline
\end{tabular}

\subsubsection{Supplementary Searches}

In addition to searches of organisational websites, we will examine how certain countries, including Russia, Canada, Gabon, the Democratic Republic of Congo (DRC), and Brazil define forests of high value in their legislation. These countries were chosen for their forest and intact forest areas.

- Government of Canada, Justice Laws Website https:/ /laws-lois.justice.gc.ca/eng/

- Federal Government of Brazil, Brazilian Legislation Portal http://www4.planalto.gov. br/legislacao/

- Government of Gabon http:/ / www.assemblee-nationale.ga/5-textes-de-reference/21 -la-constitution/

- Government of Russian Federation, Constitution Laws and Statutes http: / / archive. government.ru/eng/gov/base/54.html

- Democratic Republic of Congo http:/ / www.leganet.cd/Legislation/Tables/forets.htm

If an article cites a definition, the source of the citation will be traced and included in the systematic map if it fulfils the inclusion criteria. In these cases, articles published before 2005 will be accepted as well.

\subsection{Search Record Database}

Search results will be exported as separate databases into Mendeley. Once searches have been completed, all individual databases will be exported into EPPI-Reviewer [24] as one database. Duplicate results will be identified and removed before article screening.

\section{Article Screening}

We will screen articles in two stages: (1) title and abstract; and (2) full text. Due to limited resources, we envision that articles will not be double-screened. Instead, consistency 
checks will be performed to ensure shared understanding of the eligibility criteria among the review team.

Before commencing with the title and abstract screening, review team members will each screen 100 randomly selected articles to check the consistency of screening decisions. Here, the entire review team will apply the eligibility criteria outlined in Table 4 to the selected articles and the results will be compared and incongruences discussed. If agreement is below the $95 \%$ threshold, further rounds will be undertaken until $95 \%$ agreement is met and screening can begin. Once screening commences, if a screener is unsure whether to include an article during the title/abstract screening, the article will be moved to the next stage.

Table 4. Eligibility criteria.

\begin{tabular}{ll}
\hline Title and Abstract Stage & \\
\hline $\begin{array}{l}\text { Environment } \\
\text { Timing }\end{array}$ & $\begin{array}{l}\text { Article is within the realms of forest policy, management and } \\
\text { conservation } \\
\text { Published in or after the year } 2005\end{array}$ \\
\hline Full Text Stage & \\
\hline Phenomenon of interest & Contains an intentional definition of "forests of high value" \\
\hline
\end{tabular}

Another consistency check will be performed before starting the full text screening to ensure shared understanding of the eligibility criteria. The first ten articles will be screened by the entire review team, and discrepancies in inclusion decisions will be discussed. Any uncertain decisions during the screening will be jointly discussed by the review team to arrive at a shared decision.

If there are articles authored by members of the review team, these will be assessed by other members of the review team who are not authors of the respective article, to avoid bias in the screening process.

\subsection{Eligibility Criteria}

The eligibility criteria (Table 4) will be applied consistently at both screening stages to assess the relevance of the article.

For this systematic map, we will use an intentional definition, which specifies the necessary and sufficient conditions for something (which for us means segments describing forests) to be a member of a set (in our case a forest definition) [25]. Our necessary conditions are descriptors of forests. We have listed following initial terms to determine whether an article includes a definition or not: consider, define, meaning, delineate, describe, explain, characterise, conceptualise, signify, and refer to. Additional terms that arise will be discussed and, if relevant, included. All used terms will be included in the final report.

A separate file will be created of the excluded articles at both screening stages. Articles excluded at the full text screening stage will additionally be listed with the respective reasons for exclusion.

\subsection{Exclusion Criteria}

Articles that do not include information on the keyword terms included in the scope (Table 2) will be excluded.

Excluded from what we consider a definition in this systematic map are changes in extent such as area loss of certain forest types. Additionally, ecosystem services provided by the forest are also excluded from our definition, because these are also not elements of our scope.

\subsection{Study Validity Assessment}

We will not appraise the validity of the studies because the purpose of this systematic map is to gain an overview of the terminology in use. 


\section{Data Extraction}

Meta-data extraction and coding will be performed at the same time when full texts are considered for inclusion. Quotations of definitions for 'forests of high value' will be extracted using line-by-line coding within the EPPI-Reviewer software (https:/ / eppi.ioe.ac. uk/CMS/Default.aspx?alias=eppi.ioe.ac.uk/cms/er4\&). Definitions will be stored within a review database in the software that assigns each quotation to a specific location within the text of each PDF. If an article fulfils the inclusion criteria, the following framework will be used for metadata extraction and coding:

- Metadata

- Source of article;

- Basic publishing details (title, authors, publication year, DOI, etc.);

- Language (English/Spanish/French);

- Type of publication (journal article, report, book, etc.).

- Study attribute data

- Study location (tropical, temperate, boreal);

- Forest type(s) defined;

- Forest definition(s);

- From which actor is the definition;

- Stakeholders involved in the study;

- Source of definition.

All data extraction and coding will also be performed in EPPI-Reviewer 4 [24]. The first ten articles will be considered jointly by all review team members who are involved in data extraction to ensure shared understanding of the framework. Any incongruences will be discussed, and if necessary, the framework will be refined.

\section{Study Mapping and Presentation}

A narrative synthesis describing the evidence base will be produced. The primary output will be a catalogue of definitions for different terms associated with forests of high value. Visualisations of the data, such as bubble maps, illustrating the relationships between definitions, stakeholders, and terms for forests of high value, as well as their frequencies in the literature, will be produced using the EPPI-Mapper software [24].

Supplementary Materials: The following are available online at https:/ / www.mdpi.com/article/10 $.3390 / \mathrm{f12070876/s1,} \mathrm{File} \mathrm{S1:} \mathrm{Performance} \mathrm{of} \mathrm{the} \mathrm{search} \mathrm{string,} \mathrm{File} \mathrm{S2:} \mathrm{List} \mathrm{of} \mathrm{articles} \mathrm{used} \mathrm{to} \mathrm{test} \mathrm{the}$ performance of the search.

Author Contributions: Conceptualisation, C.A.G., P.O.W., S.S. and N.L.; methodology, S.S. and R.G.; writing-original draft preparation, N.L. and S.S.; writing—review and editing, F.K., R.G., P.O.W., C.A.G., S.S. and N.L.; supervision, S.S. and P.O.W.; project administration, P.O.W., C.A.G. and S.S.; funding acquisition, C.A.G. and P.O.W. All authors have read and agreed to the published version of the manuscript.

Funding: This research was funded by FSC International.

Acknowledgments: We thank Ida N.S. Djenontin from Michigan State University for her valuable comments on the first draft of the manuscript. Additionally, we thank the stakeholders for their involvement and useful comments in the development of the protocol.

Conflicts of Interest: The authors declare no conflict of interest.

\section{References}

1. Altamirano, A.; Aplin, P.; Miranda, A.; Cayuela, L.; Algar, A.; Field, R. High rates of forest loss and turnover obscured by classical landscape measures. Appl. Geogr. 2013, 40, 199-211. [CrossRef]

2. Chazdon, R.L.; Brancalion, P.H.S.; Laestadius, L.; Bennett-Curry, A.; Buckingham, K.; Kumar, C.; Moll-Rocek, J.; Vieira, I.C.G.; Wilson, S.J. When is a forest a forest? Forest concepts and definitions in the era of forest and landscape restoration. Ambio 2016, 45, 538-550. [CrossRef] [PubMed] 
3. FAO. The Forest Resources Assessment (FRA) Working Paper 180. Terms and Definitions; Food and Agriculture Organisation of the United Nations: Rome, Italy, 2015.

4. FAO. Global Forest Resources Assessment 2020: Main Report; Food and Agriculture Organisation of the United Nations: Rome, Italy, 2020.

5. Morales-Hidalgo, D.; Oswalt, S.; Somanathan, E. Status and trends in global primary forest, protected areas, and areas designated for conservation of biodiversity from the Global Forest Resources Assessment 2015. For. Ecol. Manag. 2015, 352, 68-77. [CrossRef]

6. Bernier, P.Y.; Paré, D.; Stinson, G.; Bridge, S.R.J.; Kishchuk, B.E.; Lemprière, T.C.; Thiffault, E.; Titus, B.D.; Vasbinder, W. Moving beyond the concept of "primary forest" as a metric of forest environment quality. Ecol. Appl. 2017, 27, 349-354. [CrossRef] [PubMed]

7. Putz, F.E.; Redford, K.H. The Importance of Defining 'Forest': Tropical Forest Degradation, Deforestation, Long-term Phase Shifts, and Further Transitions. Biotropica 2009, 42, 10-20. [CrossRef]

8. Riggio, J.; Baillie, J.E.M.; Brumby, S.; Ellis, E.; Kennedy, C.M.; Oakleaf, J.R.; Tait, A.; Tepe, T.; Theobald, D.M.; Venter, O.; et al. Global human influence maps reveal clear opportunities in conserving Earth's remaining intact terrestrial ecosystems. Glob. Chang. Biol. 2020, 26, 4344-4356. [CrossRef] [PubMed]

9. Lewis, S.L.; Lopez-Gonzalez, G.; Sonké, B.; Affum-Baffoe, K.; Baker, T.R.; Ojo, L.O.; Phillips, O.; Reitsma, J.M.; White, L.; Comiskey, J.A.; et al. Increasing carbon storage in intact African tropical forests. Nat. Cell Biol. 2009, 457, 1003-1006. [CrossRef] [PubMed]

10. Bichet, O.; Dupuch, A.; Hébert, C.; Le Le Borgne, H.; Fortin, D. Maintaining animal assemblages through single-species management: The case of threatened caribou in boreal forest. Ecol. Appl. 2016, 26, 612-623. [CrossRef] [PubMed]

11. Newton, P.; Kinzer, A.T.; Miller, D.C.; Oldekop, J.A.; Agrawal, A. The Number and Spatial Distribution of Forest-Proximate People Globally. One Earth 2020, 3, 363-370. [CrossRef]

12. Smith, M. (Peggy) A Reflection on First Nations in their Boreal Homelands in Ontario: Between a Rock and a Caribou. Conserv. Soc. 2015, 13, 23-38. [CrossRef]

13. Beacham, D.; Copping, S.; Reynolds, J.; Black, C. Indigenous Cultural landscapes: A 21st-century landscape-scale conserva-tion and stewardship framework. George Wright Forum 2017, 34, 343-353.

14. Watson, J.E.M.; Evans, T.; Venter, O.; Williams, B.; Tulloch, A.; Stewart, C.; Thompson, I.; Ray, J.C.; Murray, K.; Salazar, A.; et al. The exceptional value of intact forest ecosystems. Nat. Ecol. Evol. 2018, 2, 599-610. [CrossRef] [PubMed]

15. Pereira, L.M.; Davies, K.K.; Belder, E.D.; Ferrier, S.; Karlsson-Vinkhuyzen, S.; Kim, H.; Kuiper, J.J.; Okayasu, S.; Palomo, M.G.; Pereira, H.M.; et al. Developing multiscale and integrative nature-people scenarios using the Nature Futures Framework. People Nat. 2020, 2, 1172-1195. [CrossRef]

16. Potapov, P.; Hansen, M.C.; Laestadius, L.; Turubanova, S.; Yaroshenko, A.; Thies, C.; Smith, W.; Zhuravleva, I.; Komarova, A.; Minnemeyer, S.; et al. The last frontiers of wilderness: Tracking loss of intact forest landscapes from 2000 to 2013. Sci. Adv. 2017, 3, e1600821. [CrossRef] [PubMed]

17. Morgan, D.; Mundry, R.; Sanz, C.; Ayina, C.E.; Strindberg, S.; Lonsdorf, E.; Kühl, H.S. African apes coexisting with logging: Comparing chimpanzee (Pan troglodytes troglodytes) and gorilla (Gorilla gorilla gorilla) resource needs and responses to forestry activities. Biol. Conserv. 2018, 218, 277-286. [CrossRef]

18. Kleinschroth, F.; Rayden, T.; Ghazoul, J. The Dilemma of Maintaining Intact Forest through Certification. Front. For. Glob. Chang. 2019, 2, 72. [CrossRef]

19. Kleinschroth, F.; Garcia, C.; Ghazoul, J. Reconciling certification and intact forest landscape conservation. Ambio 2018, 48, 153-159. [CrossRef] [PubMed]

20. Garcia, C.; Savilaakso, S.; Verburg, R.W.; Gutierrez, V.; Wilson, S.J.; Krug, C.; Sassen, M.; Robinson, B.; Moersberger, H.; Naimi, B.; et al. The Global Forest Transition as a Human Affair. One Earth 2020, 2, 417-428. [CrossRef]

21. Booth, A.; Noyes, J.; Flemming, K.; Moore, G.; Tunçalp, Ö.; Shakibazadeh, E. Formulating questions to explore complex interventions within qualitative evidence synthesis. BMJ Glob. Heal. 2019, 4, e001107. [CrossRef]

22. Reid, W.V.; Mooney, H.A.; Cropper, A.; Capistrano, D.; Carpenter, S.R.; Chopra, K.; Dasgupta, P.; Dietz, T.; Duraiappah, A.K.; Hassan, R.; et al. Ecosystems and human well-being-synthesis: A report of the Millennium Ecosystem Assessment. Island Press. 2005. Available online: https:/ / agris.fao.org/agris-search/search.do?recordID=NL2012017931 (accessed on 15 January 2021).

23. Livoreil, B.; Glanville, J.; Haddaway, N.R.; Bayliss, H.; Bethel, A.; De Lachapelle, F.F.; Robalino, S.; Savilaakso, S.; Zhou, W.; Petrokofsky, G.; et al. Systematic searching for environmental evidence using multiple tools and sources. Environ. wvid. 2017, 6, 23. [CrossRef]

24. Thomas, J.; Graziosi, S.; Brunton, J.; Ghouze, Z.; O’Driscoll, P.; Bond, M. EPPI-Reviewer: Advanced Software for Systematic Reviews, Maps and Evidence Synthesis; EPPI-Centre Software; UCL Social Research Institute: London, UK, 2020.

25. Cook, R.T. Intensional Definition. In A Dictionary of Philosophical Logic; Edinburgh University Press: Edinburgh, Scotland, 2009; p. 155. 